\title{
Maintainer Perspectives on Data-driven Transport Asset Management and the Future Role of the Internet-of-Things
}

\author{
MIKE HARDING, School of Computing \& Communications, Lancaster University, UK \\ MARK ROUNCEFIELD, School of Computing \& Communications, Lancaster University, UK \\ NIGEL DAVIES, School of Computing \& Communications, Lancaster University, UK
}

In this paper we present fieldwork findings from engagements with a cooperative group of strategic and operations transport maintainers, responsible for the maintenance of drainage infrastructure to mitigate the risk and impact of flooding on the network. Through transport maintainer perspectives from rail and highways sectors, we focus on developing an understanding of work-practices in the context of transport surface-water management, and how the recent acceleration towards 'data-driven' technologies in support of maintenance intervention decision-making (i.e. the work of coordinating the cleaning of drainage) is integrated and impacting on current work-practice. Furthermore, we document and consider how maintainers perceive the potential role of the Internet-of-Things (IoT) and highlight emerging opportunities and tensions that may arise ahead of its future design and implementation.

CCS Concepts: $\bullet$ Information systems $\rightarrow$ Data analytics; $\bullet$ Human-centered computing $\rightarrow$ Empirical studies in collaborative and social computing.

Additional Key Words and Phrases: Decision-support; Internet-of-things; Information Systems; Transport; Infrastructure Maintenance

\section{ACM Reference Format:}

Mike Harding, Mark Rouncefield, and Nigel Davies. 2019. Maintainer Perspectives on Data-driven Transport Asset Management and the Future Role of the Internet-of-Things. Proc. ACM Hum.-Comput. Interact. 3, CSCW, Article 112 (November 2019), 20 pages. https://doi.org/10.1145/3359214

\section{INTRODUCTION}

Inefficient urban surface-water management approaches in the UK are projected to contribute to a 50\% increase in 'expected annual damages' (EAD) as a direct result of flooding by 2080 [32]. Major weather events such as storm Desmond in 2015 have highlighted the impact more severe flood events can cause, particularly across the UK's transport network [38], with widespread disruption to journeys, environmental damage, and contractual fines on organisations responsible for maintaining critical transport infrastructure.

To mitigate the impact of flooding, an intricate network of road and rail-side drainage exists to remove water from road surfaces and rail catchment areas, with maintainers undertaking ongoing work to ensure drainage assets are clear and operating at capacity. However, with limited resource available to transport maintainers, traditional work-practices involved in the coordination

Authors' addresses: Mike Harding, m.harding@lancaster.ac.uk, School of Computing \& Communications, Lancaster University, UK, Infolab21, South Drive, Lancaster, Lancashire, LA1 4WA; Mark Rouncefield, m.rouncefield@lancaster.ac.uk, School of Computing \& Communications, Lancaster University, UK, Infolab21, South Drive, Lancaster, Lancashire, LA1 4WA; Nigel Davies, n.davies@lancaster.ac.uk, School of Computing \& Communications, Lancaster University, UK, Infolab21, South Drive, Lancaster, Lancashire, LA1 4WA.

Permission to make digital or hard copies of part or all of this work for personal or classroom use is granted without fee provided that copies are not made or distributed for profit or commercial advantage and that copies bear this notice and the full citation on the first page. Copyrights for third-party components of this work must be honored. For all other uses, contact the owner/author(s).

(C) 2019 Copyright held by the owner/author(s).

2573-0142/2019/11-ART112

https://doi.org/10.1145/3359214 
of drainage maintenance such as cleansing road-side drains of silt build-up, are becoming ineffective in the face of unprecedented shifts in climate and increasing numbers of travellers on the network. Furthermore, highly reactive maintenance practices across the sector are at present compounded by a limited awareness of remote drainage asset condition and behaviours over time. Since the UK Government's review of flood management processes and subsequent introduction of the Flood and Water Management Act 2010 [8], the Department for Transport (DfT) has encouraged managing transport authorities to consider alternate data-driven approaches to surface-water management in order to deliver more efficient, low-cost services [6].

The drive for datafication [28] of drainage maintenance, a traditionally labour-intensive cooperative work setting, is leading to technical advances (i.e. pervasive data collection, predictive analytics and automation) that are increasingly considered without a clear understanding of the social perspectives towards existing data application and organisational practices supported by existing technologies (i.e. decision-support tools). In particular, as drainage maintainers attempt to shift from manual to increasingly more real-time, proactive methods, we believe it is particularly timely that an understanding of 'data work' [12] in this domain is characterised to better inform the design of emerging data-driven coordination services.

In this paper we present fieldwork findings gathered over a two-year period through a series of engagements (i.e. interviews and observation) with strategic and operational transport maintainers. Our work aims to begin to address the gap in understanding how maintainers perceive current planning practices, employ decision-support tools and operationalise data to guide strategic and operational decisions. Through this understanding, we highlight emerging tensions and opportunities with regard to the future adoption of data-driven technologies, and discuss our fieldwork findings in relation to key CSCW concepts (i.e. articulation work, awareness, data work) that appear particularly relevant to understanding the impact of IoT capabilities on cooperative work.

\section{TRANSPORT DRAINAGE MAINTENANCE}

Prior to the severe floods of 2007 [1] and introduction of new flood management policies [6], the role of data and technology as a means to support more effective surface-water management within the transport sector had received little consideration. Indeed, until recently custodians of major transport infrastructure including the government agency for maintaining the rail network, perceived drainage asset management as a relatively low priority practice in contrast to the upkeep of more 'critical' assets such as track and signalling. Beyond 2007 managing authorities have begun to shift focus towards drainage management with new organisational resources available, including the national rail 'safety, technical and engineering' strategic (STE) group that encompasses a mandate to deliver improvements in the way drainage assets are maintained to minimise accident risk [35]. Within highways, drainage maintenance has seen little innovation up until recently, where industry-led research has begun to explore challenges of open access to maintenance data repositories [24], issues of mistrust between public, local authority and maintenance stakeholders [5] and security implications of cyber-physical systems in maintenance [25]. Such endeavours demonstrate the growing willingness of managing highways authorities to consider the potential opportunities and challenges of more data-driven maintenance approaches.

What is apparent through our engagements with highways maintainers has been the evolution in the way drainage maintenance is performed, shaped by a growing need to understand more deeply the condition and behaviour of drainage assets, facilitated through data. Indeed, with greater awareness of the network, maintainers have begun to recognise the benefits a richer view of the drainage network can have on service performance to facilitate shifts from static, to more proactive maintenance schedules. 
Maintainer Perspectives on Data-driven Transport Asset Management and the Future Role of the Internet-of-Things

A common cyclical maintenance process in highways and rail is the cleansing of pot drains (known as gullies in highways and catch-pits in rail) that line streets and rail-track to remove surface water. These drainage assets often develop large deposits of silt and debris that must be removed in order to ensure asset performance and avoid flood incidents. Although, while this approach to cyclical cleansing is comprehensive, it is also perceived to be highly inefficient, where often free-flowing gullies or clear catch-pits are visited without requiring care. Similarly, pluvial flooding can occur as a result of rapid silt build-up, yet at present maintainers lack an in-depth understanding of individual drainage behaviour patterns to proactively coordinate maintenance and target problem assets prior to forecasted weather events.

The transition towards more 'data-guided' forms of drainage maintenance is placing new expectations on workers, to leverage technology and data, who have traditionally operated within analogue work settings composed of manual-repetitive maintenance tasks. Moreover, the widespread availability of mobile communications and low-cost in-field devices has led to significant effort both in rail and highways to digitise activities such as remote works order management and asset risk assessments, a once pen and paper dominant set of activities, that now require workers to formally collect asset maintenance information gathered through handheld devices. A particular, side-effect of maintenance datafication and the growing silos of asset information, is the need for maintainers to consider how best actionable knowledge can be extracted from such data, and effectively integrated within a complex cooperative work setting to support a range of strategic and operational decision-makers with diverse information needs.

To assist maintainers in this transitional phase from manual to automated data collection, slow to rapid knowledge provision and corrective to prescriptive maintenance, maintainers and information system practitioners first require an awareness of the social perspectives towards current processes, technology and data use that we report on here.

\section{RELATED WORK}

Emerging from work involving energy advisors, data work [12] a nascent area of CSCW research that attempts to broaden the understanding of "social practices in and through which IoT data is accountably collected, used and acted upon" [11] provides a suitable lens in which to focus our research. Therefore, we align with Fischer et al's motivations in attempting to address the "arguably underdeveloped" [11] perspective of data work but situated within the highly cooperative work of drainage surface-water management. Although, here we attempt to apply a much broader investigative lens, that encompasses engagements with a diverse range of actors across two sectors. In particular, our contribution stands apart, both in terms of the work context, where prior CSCW research, with the exception of Liu et al. [39], appears to have bypassed cooperative work concerns of drainage maintenance, and approach, where we attempt to understand the present and future roles of data and decision-support technology prior to any technological design probe through ethnomethodological and speculative means [40] detailed in section 4.

In review of the literature, Liu et al. document some of the unforeseen challenges to the deployment of mobile wireless technology to drainage and wastewater systems in Seattle, outlining longstanding failures in organisational communication concerning functionality, workflow, and some of the unrecognised but important tacit features of work. Beyond work in CSCW related to drainage we have identified several investigations focused on understanding aspects of infrastructure asset management (i.e. common practice, decision models [10] and information systems) across Utilities [16], Healthcare [21], Civic [34] and Transport [29] sectors.

Through our own history of engaging with transport maintenance organisations, exploring issues of data sharing and the trustworthy design of information systems [4, 5, 30] has provided an invaluable outpost over the past decade to observe the slow, but emerging evolution of transport 
maintainers towards what Penn [33] would describe as data-aware or data-guided organisations. Indeed, this recent shift has given rise to a growing interest in the potential opportunities of IoT analytics, to support more informed drainage planning and decision-making. Therefore, given the current climate and appetite for such a shift, our research has a particular focus on workpractice [9] that draws on a formative study of fieldwork that aims to provide a social and practical understanding of current drainage maintenance practice, and examines attitudes on future datadriven approaches from the perspectives of maintainers, to advance the emerging discourse around IoT systems design research and wider CSCW concerns. In particular, prior work around CSCW and the IoT [43] has aided in summarising how CSCW concepts and approaches can help inform an understanding of the IoT's role in cooperative work. Aspects of awareness [13], articulation work [20], "local contexts" and "information spaces" represent important concepts in understanding the complex interdependencies between "objects and spaces" (i.e. sensors in remote drainage assets), data, organisational policy, tools and decision-makers that embody drainage maintenance work.

Related to our discussions detailed in section 6, the ability of an organisation's 'responsiveness' to rapidly emerging knowledge and awareness of the drainage network [13] are studies that have identified essential elements in asset management, such as effective information services, flexible regulatory policies and revised processes [44] that can enable organisations to shift direction from reactive to more proactive entities [37] facilitated through data. In addition, several works including [27] have considered the tension of harnessing economic value from proactive decision-support services in light of budgetary limitations imposed on maintainers that hamper the execution of data-guided intervention plans, a particular challenge reflected in our findings.

Halfawy's work [26] on the integration of asset management processes emphasises the importance of effective integration between "data, processes and software systems" to facilitate wider adoption and acceptability of proactive data-driven decision-support tools. In particular Halfawy's challenges of data and technology fragmentation resonate with our findings that highlight how current drainage maintenance practice suffers from significant fragmentation in the provision of data and technology across strategic and operational roles.

Finally, a number of previous works have studied the novel application of IoT technologies across several industries [22] with particular examples focused on the design of IoT systems to support smarter urban water management practices [42] and delivering greater efficiencies in 'smart city' environments [31]. In contrast, through a speculative approach in the form of future scenarios played out with maintainers, we focus less on the technical challenges of designing IoT systems and consider more the potential opportunities and social challenges of the IoT through the perspectives of drainage operatives.

\section{METHOD AND ANALYSIS}

To develop our understanding of transport drainage maintenance we conducted semi-structured interviews and observation sessions with highways and rail operatives involved in the planning and delivery of drainage maintenance interventions. Through a series of shadowing (i.e. think aloud [15]), telephone and one-on-one interviews we focused our discussion around aspects of maintenance planning, the decisions operatives performed and the information technology (IT) that supported them. Participant selection was informed by an established research champion affiliated to each drainage managing authority that proved invaluable in coordinating interview logistics and mitigated the common challenges of studies involving large-scale organisations.

\subsection{Participant Roles, Responsibilities \& Organisational Hierarchies}

Table 1 lists the 9 participants we interviewed to provide an understanding of sector affiliations, roles and responsibilities within each organisation. More broadly, participants were categorised as 
Maintainer Perspectives on Data-driven Transport Asset Management and the Future Role of the Internet-of-Things

Table 1. Profile of Maintenance Participants

\begin{tabular}{|c|c|c|c|c|c|c|}
\hline Ref & Sector & Area & Division & Position & Role & Responsibilities \\
\hline P1 & Highways & Local & $\begin{array}{l}\text { Asset Man- } \\
\text { agement }\end{array}$ & $\begin{array}{l}\text { Transport As- } \\
\text { sets Manager }\end{array}$ & Strategy & $\begin{array}{l}\text { Asset resource invest- } \\
\text { ment \& allocations }\end{array}$ \\
\hline P2 & Highways & Local & $\begin{array}{l}\text { Risk Man- } \\
\text { agement }\end{array}$ & $\begin{array}{l}\text { Flood Risk } \\
\text { Manager }\end{array}$ & Strategy & $\begin{array}{l}\text { Flood risk mitigation; } \\
\text { Road drain management }\end{array}$ \\
\hline P3 & Highways & Local & $\begin{array}{l}\text { Asset Main- } \\
\text { tenance }\end{array}$ & $\begin{array}{l}\text { Highways } \\
\text { Maintainer }\end{array}$ & Operations & Scheduling maintenance \\
\hline $\mathrm{P} 4$ & Rail & $\begin{array}{l}\text { Route } \\
\text { Segment }\end{array}$ & $\begin{array}{l}\text { Maintenance } \\
\text { Delivery Unit }\end{array}$ & $\begin{array}{l}\text { Maintenance } \\
\text { Coordinator }\end{array}$ & Operations & Scheduling maintenance \\
\hline P5 & Rail & Route & $\begin{array}{l}\text { Asset Man- } \\
\text { agement }\end{array}$ & Asset Manager & Strategy & $\begin{array}{l}\text { structural investment } \\
\text { planning; mainte- } \\
\text { nance guidance }\end{array}$ \\
\hline P6 & Rail & Route & $\begin{array}{l}\text { Asset Man- } \\
\text { agement }\end{array}$ & Asset Manager & Strategy & $\begin{array}{l}\text { structural investment } \\
\text { planning; mainte- } \\
\text { nance guidance }\end{array}$ \\
\hline P7 & Rail & Route & $\begin{array}{l}\text { Asset Man- } \\
\text { agement }\end{array}$ & $\begin{array}{l}\text { Senior Asset } \\
\text { Engineer }\end{array}$ & Strategy & $\begin{array}{l}\text { structural investment } \\
\text { planning; mainte- } \\
\text { nance policy plans }\end{array}$ \\
\hline P8 & Rail & Route & $\begin{array}{l}\text { Asset Man- } \\
\text { agement }\end{array}$ & Asset Manager & Strategy & $\begin{array}{l}\text { structural investment } \\
\text { planning; mainte- } \\
\text { nance policy plans }\end{array}$ \\
\hline P9 & Rail & National & $\begin{array}{l}\text { Safety, Technical } \\
\text { \& Engineering }\end{array}$ & Engineer & Strategy & $\begin{array}{l}\text { drainage management } \\
\text { policies \& standards; }\end{array}$ \\
\hline
\end{tabular}

undertaking either i) strategic-level activities such as the assessment of drainage asset performance to inform long-term drainage renewal and maintenance strategies, or ii) operations-level tasks that included the delivery of manual maintenance activities such as cleaning blocked drainage. Rail sector participants P5, P6 and P7 sat across 3 of the 10 strategic geographical routes' in the UK responsible for providing 'route' bounded asset management, while coordinating with several underlying delivery units (P4) tasked with performing maintenance within designated segments of a route. P9 operated at a national-level as part of the 'safety, technical \& engineering' division overseeing the implementation of drainage management guidance policies in collaboration with route-level asset managers. Within highways the responsibility of day-to-day drainage management was undertaken by a team of asset maintainers with work often informed by strategic guidance from both transport asset and flood risk management teams.

\subsection{Participant Engagement}

A diverse group of individuals were recruited that represented a broad cross-section of strategy and operation level roles. In rail, 4 semi-structured telephone interviews with strategic drainage engineers and route-level asset managers were performed along with two site visits to observe a route asset manager and maintenance delivery coordinator. In highways, we conducted three telephone interviews with individuals performing i) strategic asset management, ii) highways maintenance and iii) flood risk management.

Following a grounded approach [2] we aimed to derive a broad but varied set of stakeholder perspectives on the ways in which transport drainage maintenance work is conducted at present. To achieve this we prioritised variability in participant characteristics (i.e. sector, role, position, area), although we recognise that for particular roles we report on (in section 5) a focus on engaging with a broad set of participants came at the cost of redundancy in terms of the number of workers 
we spoke to undertaking a similar role. For example, given the challenges of arranging visits particularly with manual operatives, we visited and engaged with a single rail route delivery unit, and subsequent maintenance coordinator (P4). Although for other roles such as at a route-level we spoke with multiple asset managers undertaking the same work but across different geographical areas of the network. Therefore, while we recognise a small sample size for particular roles could represent a shortcoming of the research, our objective of sampling a diverse range of stakeholder perspectives has allowed us to understand maintainer attitudes and behaviours through a broader investigative lens. Indeed, we are unaware of previous research that has attempted a methodological approach to understand drainage maintenance work with such a diverse range of actors across multiple transport modalities.

For telephone and workplace engagements we followed a similar semi-structured interview protocol to guide our discussions with questions exploring aspects of maintenance work that focused on understanding i) 'process and workflows' including questions such as 'how does your role support the process of drainage maintenance?' and 'describe the current routines involved in drainage maintenance scheduling and delivery', ii) 'information use' investigating 'what information is critical to drainage maintenance coordination?', and iii) 'access to technology' such as 'what technology do you leverage if any to support your day-to-day decision-making?'. Beyond questions that aimed to develop an understanding of current data and technology use, we were further driven to explore stakeholder attitudes towards emerging data-driven approaches to maintenance, and understand worker views towards remote drainage condition monitoring and automated work scheduling. For phone interviews, participants received a description of a near-future scenario of an intelligent drainage management system that incorporated the use of remote data collection through sensors, and automated reporting of potential faults (i.e. flooding) ahead of time. In addition, for site visits, the same scenario was provided along with further support materials that included visualise mock-ups of predictive analytics dashboards. In particular, participants were encouraged to reflect and discuss the potential challenges and opportunities of adopting such approaches given their understanding of how current maintenance is performed.

\subsection{Data Analysis}

Overall our analysis focused on understanding current approaches to drainage maintenance, the role of data and information technology in decision-making, and attitudes towards the utility of real-time asset condition monitoring and automated maintenance planning. We systematically coded for behavioural and attitudinal perspectives of drainage maintenance planning, reflections on available information technology to support decision-making along with perceived challenges and opportunities in the usage of IoT capabilities to enable predictive and prescriptive maintenance. Each engagement activity was audio recorded, transcribed and collated using a qualitative data analysis software package (nVivo 12), enabling an iterative coding and categorisation process to identify prominent themes and concepts from participant responses. Participant transcripts were imported into $\mathrm{nViVo}$ and tagged with participant metadata describing associated sector, role and position along with a pseudo-randomised identifier. Linking such metadata provided a means to associate emerging themes to worker characteristics as part of our analysis. For example, participant perceptions of reliability and trust in asset inspection information between strategic and operational roles highlighted particular conflicting viewpoints of interest to our findings. We undertook an initial open coding phase focused on identifying participant responses that related to four primary threads of investigation that included participant references to i) the application of 'data and information', ii) appropriation and examples of technology use, iii) decision-making and iv) both positive and negative response related to the near-future scenario of continuous remote monitoring and automation in drainage maintenance. Finally, we employed a line-by-line coding phase to elicit 
Maintainer Perspectives on Data-driven Transport Asset Management and the Future Role of the Internet-of-Things

a number of related sub-topics we coded for that were subsequently sorted and grouped within the higher-level codes previously outlined. We inductively generated code references across all transcripts that provided a basis on which to construct narratives related to our research questions of understanding worker perspectives on technology, decision-making and automation highlighted in the following section.

\section{MAINTAINER PERSPECTIVES ON PRACTICE, TECHNOLOGY \& DATA}

In this section, we report on rail and highway approaches to drainage maintenance planning, the availability and application of state-of-the-art decision-support technologies, and worker perspectives on explicit data use to guide maintenance decisions.

\subsection{Maintenance Scheduling}

During our interviews we asked participants to describe their experiences of engaging in drainage maintenance scheduling, the stakeholders involved, and resources (i.e. standards, tools and data) available to support their respective roles. Overall, scheduling processes were viewed as highly reactive, dominated by short-term triage of emerging problems (i.e. flooding) through corrective maintenance work, such as 'pumping' and 'cleansing' drains, along with longer-term planning of cyclical inspection regimes. The following quote from a maintenance coordinator summed up the general sentiment of how drainage maintenance was perceived in rail and highway domains, as a predominantly reactive operation, constrained by limited resources:

“... totally reactive, one! our staffing levels are so low anyway, we are not proactive with [maintenance work], we are not proactive with any work we do. Off-track is totally a fire-fighting and reactive organisation (P4)..."

Central to maintainers desire to plan and better coordinate maintenance activities, was the need to effectively manage the risk of drainage failures across the transport network and the potential side-effects (i.e. commuter safety and delays) on critical infrastructure. In particular, the general consensus was that only recently had drainage risk management become a priority for maintenance authorities. Long-term cyclical maintenance scheduling appeared to be the primary solution to manage aspects of risk associated with the drainage network, although rail and highways strategies for managing risk appeared to vary significantly.

Rail maintainers relied on a standardised drainage asset risk model (outlined in the internal 'CP5 Drainage Asset Policy - SBPT3017' document) used to guide cyclical maintenance policies for individual assets based on manually inspected condition scores.

“... there's a model that they [Delivery Unit Management] can use to decide how high risk a catch pit is (P9)..."

In particular, this model allows maintainers to better decide how frequently drainage assets should be visited and the types of intervention work employed such as i) the implementation of periodic on-site inspections, ii) 'line-of-sight' surveys of track segments, iii) maintenance work such as 'jetting' to clean drains of silt build-up, and iv) in extreme cases the replacement and renewal of assets considered 'beyond' maintenance.

For council authorities responsible for highways assets, contractual agreements with third-party maintainers appeared to dictate how frequent gully cleansing was performed, with a predominantly static approach to risk management. A manager responsible for asset management within the council noted that their contract with maintainers only mandated that they visit each of their over 45,000 gullies once a year:

\footnotetext{
"... the contract is just clean every gully once a year (P2)..."
} 
In many ways, the apparent shortcoming in standards and guidance for highways drainage management has led to contract terms dictating the amount of work maintainers are willing to perform, shaped by cost and budget availability.

For more short-term scheduling of maintenance typically at weekly intervals, maintainers reported planning situations where asset condition reports from inspectors and environmental data (i.e. weather forecasts) played a particular role in supporting more reactive scheduling activities.

"... we have a weekly triage meeting, for every issue that comes in to us via email or telephone conversations or personal encounters... every week we sit down as a group, all 4 of us and we review everything that's come in and put a risk score against them. And then we decide what we're going to do. Often, we'll get an event like snowfall, and the snow melts, which sends us into tailspin. So, we have to be reactive and make lots of phone calls and drop the day job really. (P7)..."

The above quote from a route-level drainage engineer frequently leveraged asset condition scores (provided on a scale of 1-5, where one is considered poor) captured by in-field inspectors to assist their own prioritisation of maintenance work.

"... well usually they use the inspection data to say right which ones to do first, so if the scores are $4 s$ or $5 s$ they will usually do those ones first. And then during the inspection the inspector if they want to raise a work order for the catch pit they will put a prioritisation score on it (P9)..."

In highways, collaboration between maintainers and the Council's internal flood risk management teams highlighted what appeared to be a relatively ad-hoc process of undertaking a multi-factor analysis of weather forecast, asset condition and road criticality information to produce a prioritised list of high risk drain 'hotspots' that enabled maintainers to target problem drains prior to an incoming weather event.

“... we're [flood risk management team] not the guys who run the actual operations side... of doing the cleansing so we would feed this info to people like [anonymous] in Highways Maintenance... and they would decide whether or not to act upon that... we would just do a crude analysis to highlight the gullies that if you have the available resources and feel that it is necessary that's where you should target the crews to go out...pre-emptively (P2)..."

At an operational level, we encountered general scepticism of the reliability of business intelligence information sourced from strategic level teams, such as flood risk management (in the example above), and the apparent tension between managing operational budgets and proactively acting upon the data. While for strategic-level operatives, attempts to influence maintenance planning through data, was particularly challenging due to the perceived latency in the offline development and delays in the delivery of actionable information to be able to mitigate problems ahead of time.

“... they often can't act on the information... if we can't give them the information in time then they can't get the gully cleansing crew out to deal with it (P2)..."

For rail maintainers, the ability to respond to sudden changes in environmental conditions and impact assessments, evidenced through manual inspection data, appeared particularly challenging due to existing work planning rules that involve extended lead times in requesting and attaining access to track sites, and the will of maintainers to minimise disruption to rolling stock caused by the need to enforce temporary speed restrictions to safeguard operative safety. 
Table 2. Transport Drainage Management Support Systems

\begin{tabular}{|c|c|c|c|c|}
\hline Name & Purpose & Description & Sector & Software \\
\hline Ellipse & $\begin{array}{l}\text { Data Manage- } \\
\text { ment \& Reporting }\end{array}$ & $\begin{array}{l}\text { Centralised repository that supports storage and } \\
\text { reporting of drainage asset information }\end{array}$ & Rail & Generic \\
\hline MyWork & $\begin{array}{l}\text { In-field Data } \\
\text { Collection }\end{array}$ & $\begin{array}{l}\text { Mobile application that supports the in-field recording and syn- } \\
\text { chronisation of asset information during inspections to Ellipse }\end{array}$ & Rail & Bespoke \\
\hline $\begin{array}{l}\text { Drainage } \\
\text { Decision- } \\
\text { Support Tool }\end{array}$ & $\begin{array}{l}\text { Analytics \& } \\
\text { Reporting }\end{array}$ & $\begin{array}{l}\text { Desktop application that analyses asset data in Ellipse and } \\
\text { provides analytics to support maintenance planning }\end{array}$ & Rail & Bespoke \\
\hline Polestar & $\begin{array}{l}\text { In-field Data } \\
\text { Collection \& } \\
\text { Reporting }\end{array}$ & $\begin{array}{l}\text { Drainage asset management system that supports the } \\
\text { remote mapping and inspection of drainage networks } \\
\text { including fault detection through a web dashboard }\end{array}$ & Highways & Generic \\
\hline Confirm & $\begin{array}{l}\text { Data Manage- } \\
\text { ment \& Reporting }\end{array}$ & $\begin{array}{l}\text { Enterprise asset management system used to } \\
\text { store and report highways asset information } \\
\text { and coordinate maintenance activities }\end{array}$ & Highways & Generic \\
\hline Inspections & $\begin{array}{l}\text { In-field Data } \\
\text { Collection \& } \\
\text { Reporting }\end{array}$ & $\begin{array}{l}\text { Drainage assessment framework that supports in- } \\
\text { field asset inspections through a mobile application } \\
\text { and map-based data visualisation tool }\end{array}$ & Highways & Generic \\
\hline $\begin{array}{l}\text { Geo-RINM (Rail } \\
\text { Infrastructure } \\
\text { Network Model) } \\
\text { Viewer }\end{array}$ & $\begin{array}{l}\text { Analytics \& } \\
\text { Reporting }\end{array}$ & $\begin{array}{l}\text { Spatial mapping tool that visualises descriptive } \\
\text { information related to rail assets }\end{array}$ & Rail & Bespoke \\
\hline
\end{tabular}

\subsection{Data \& Decision-Support Tools}

Drainage authorities in rail and highways are presently active in developing integrated asset data management services that enable operatives to collect, analyse and represent asset information to support drainage management activities.

Each organisation we engaged with implemented a range of generic asset data management and mobile data collection applications (summarised in table 2) but only rail maintainers appeared to have access to more bespoke decision-support tools. In the following section we examine maintainer perspectives on the use of available technology in asset data collection and analytical tools to inform their work.

5.2.1 Data Collection. The cyclical inspections of gullies and catch-pits allow maintainers to collect explicit knowledge (i.e. knowledge that is easy to articulate, write down, and share) about asset behaviours such as changes in silt build-up over time. As highlighted previously, we found on-site inspections to be driven in part by contractual agreements or risk models that informed the frequency of assessments. Strategic-level operatives (i.e. route asset managers) emphasised the positive effect in-field data collection processes had delivered in improving the quality and availability of asset data available, but stressed the importance of continuing to work on improving data collection and address issues of incomplete data to better support downstream analytical activities.

“... incomplete asset data is a major problem. We're actively working to improve data quality through the use of MyWork and Polestar...(P8)"

In highways, 'Inspections' was generally deemed to be an effective tool in supporting asset assessments, although a highways maintainer (P3) noted difficulties of ensuring maintenance crews correctly logged in and out of the application before sharing tablet devices. In particular, this issue often led to problems when attempting to corroborate third-party accounts (i.e. from the public) of gully conditions against explicit asset information captured through Inspections: 
"... what the crews have done in the past... if some of them are off sick they'll give the iPad to somebody else but they won't change the name of the person putting in the information... because I've had this with some of the crews before... where I've phoned them up and said look you've put on this gully that you cleansed it on such and such a date and the person in the house is claiming that's it's still blocked and flooding...(P3)"

Attitudes towards the use of mobile and web-based asset data collection systems MyWork and Polestar varied across strategic and operational levels, with MyWork preferred as a tool to manage planned works (i.e. creating, opening and closing maintenance jobs) while Polestar was viewed more favourably when performing inspections:

"... we use myWork for recording the work you've completed and the work that is requiring to be done...(P4)"

For particular rail 'routes' the option to employ both asset data collection systems provided an opportunity to review the benefits and limitations of each. A particular challenge expressed by in-field operatives was the interaction time required to collect asset information through MyWork that could often take "over 20 minutes":

"... So, now that is quite an onerous job. So, you stand over a catch-pit and there are 26 questions to answer. That then, once you've answered those questions, you measure the size, measure this, that and the other, that then goes off into the system...(P4)"

More minor technical issues related to the use of MyWork included the reported negative impact on device battery life, and the inability to view a maintainer works orders bank (i.e. list of scheduled jobs) beyond a particular point in time. With maintenance crews only afforded short time windows to perform interventions, maintainers generally felt speed and accuracy of data collection were essential capabilities of any asset inspection application.

5.2.2 Drainage Analytics \& Modelling Tools. Rail decision-makers had access to a small number of bespoke drainage analytics tools that attempted to support strategic and tactical maintenance planning. Although overall, maintainers reported infrequent use of such tools to support decisions and planning. For example, the Drainage Decision-Support Tool (DDST) was originally designed to encapsulate a set of tactical models to assist the day-to-day prioritisation of drainage maintenance, driven by asset condition information held in Ellipse. Indeed, we were unable to identify examples where the DDST was used to support day-to-day scheduling of maintenance. More significantly, route asset managers reported only ad-hoc use of the DDST as a tool to provide evidence for capital investment proposals for major infrastructure upgrades. Moreover, maintainers found the tool's spreadsheet-like interface to be complex and difficult to use:

“... [DDST's] a fiendishly big complicated spreadsheet it brings together Ellipse drainage data and off-track drainage data from the earthworks database. [It generates] risk [scores] according to the 5 by 5 matrix and spits out according to policy what we should do...(P7)"

While rail maintainers did not appear to use the DDST to guide short-term weekly maintenance planning decisions, it does represent an attempt to provision tools that allow maintainers to begin to extract knowledge from the underlying silos of asset inspection data. This is in contrast to maintenance planning within the highways sector, where offline, generic tools such as Excel were still commonplace, used to calculate individual flood risk scores of gully drains manually using several pieces of information (i.e. asset condition, weather forecasts) to shape short-term planning decisions. Understanding the reasons why rail maintainers did not at present fully adopt the DDST and other drainage analytics capabilities such as Ellipse's in-built reporting functionality for more short-term maintenance planning were of particular interest in our discussions. 
Maintainer Perspectives on Data-driven Transport Asset Management and the Future Role of the Internet-of-Things

"... the DDST is seldom used for day-to-day planning DDST is limited in terms of the factors it accounts for when generating risk scores. I'll sometimes use the DDST to forecast renewals during control period budgeting...(P8)"

Participants indicated several factors that limited their usage including the DDST's complex user interface, concerns over the validity and relevancy of its analytic output and incomplete representation of risk model factors that were not accounted for such as the 'track criticality' (i.e. the importance of a track segment in terms of usage) a drain resided on. Decision-makers concerns over the validity of the data in the DDST were in part related to the once a year updating of the flood risk metrics based on the latest condition data held in Ellipse:

“... The DDST doesn't take into account local factors, it doesn't take into account flooding, or flood risk, it doesn't take into account nuisance or problems that third parties have with this...(P7)"

Indeed, maintainers reported a number of cases where the DDST would allocate high priority scores to drainage assets in need of maintenance on track segments that were perceived to be of low importance, where the cost of maintenance would outweigh the perceived benefit of undertaking the work.

5.2.3 Drainage Visualisation \& Reporting Tools. The widespread uptake and adoption of mobile collection and data management technologies within the rail and highways sector appeared to be in contrast to that of visualization and reporting tools available to maintainers. In rail, we found of the tools discussed, including Polestar and Geo-RINM Viewer, maintainers primarily used them as part of a manual verification step to corroborate asset information captured by in-field operatives. For example, this process was illustrated by a maintenance delivery coordinator during our interview session who highlighted a recent case via Polestar where a series of assets had been collected erroneously and required further correction.

“...So, you see he's [Data Collector] put one catch-pit there, one catch-pit there, one, and then as you get here, you've got a whole mash of stuff crossing from side to the other. That's purely because he's only walked down one side of the line, because the catch-pits are actually here and here...(P4)"

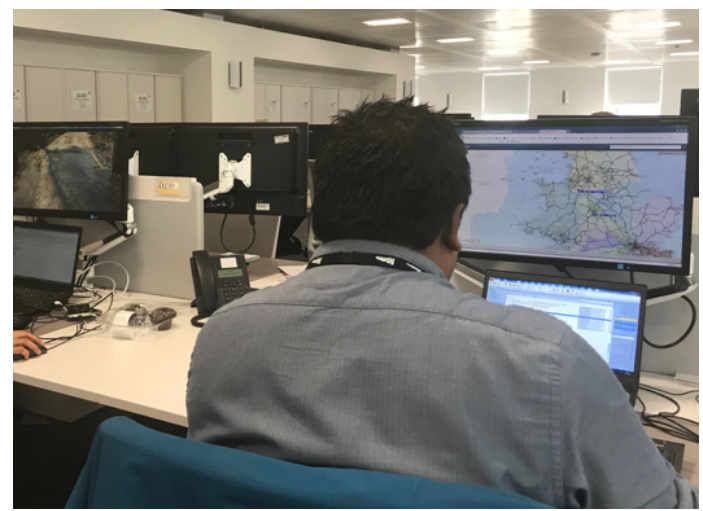

Fig. 1. Observed usage of Geo-RINM Viewer by a route asset manager

Beyond examples of verifying collected asset information, typically against tacit knowledge of the drainage infrastructure, maintainers would often use these tools to extract information 
for evidencing renewal proposals for new drainage infrastructure. General attitudes towards visualisation tools were one of frustration, particularly with the slow response times of map interactions in Geo-RINM map viewer (see Fig. 1) and limited flexibility in generating different analytical reports from the underlying asset data in Ellipse.

“... it's [Ellipse] not particularly easy, it's okay, it is accessible but um, there's only certain reports that you can get at the moment it takes a long time to download [data] um and it's not particularly easy to be honest ... (P9)"

Others felt essential features were missing that made it challenging to understand the reliability of the data shown. For example, route-level management highlighted the need for the DDST to include a time element to indicate the relevance of condition scores displayed, along with a mechanism to show asset condition histories.

"... there is no temporal dimension to the presented data in DDST...(P8)"

In highways, asset managers similarly noted the importance of tools that supported exploration capabilities of asset condition histories in order to support maintenance planning:

"... [the app] that the guys use gives you the history of it [manual asset condition], they find that really useful...(P2)"

\subsection{Drainage Network Knowledge \& Maintainer Decisions}

The application of information and knowledge to support coordination decisions was commonplace across both domains. This reflected the tentative shift within the surface-water management towards 'e-Maintenance' [3] and the growing availability of information services heightening the remote awareness of infrastructure assets. In rail, planning of strategic maintenance such as cyclical inspection regimes were primarily informed through explicit knowledge derived through the application of manual asset condition information held in a centralised asset data repository. Although, while explicit information use was commonplace in evidencing strategy decisions, such as applications for capital infrastructure investment and the renewal of underperforming drainage assets, at an operational level it was felt maintainers often bypassed explicitly available knowledge such as manual inspections accessible in Ellipse for tacit knowledge and experience during maintenance triage:

“... [Operational] maintenance don't use the drainage data in Ellipse at all. So, when they get a drainage problem if they do anything, they will just raise a work order and close it down. They won't relate that activity to the data, the asset data which is very frustrating...(P7)"

Moreover, the following quote exemplified operational maintainers tendencies to utilise past experience and tacit knowledge over explicit asset knowledge available in Ellipse:

"... that is just going by me going well that is the one, we have had flooding there, we fixed the catch-pit, but we know that is going to block again, because I went there a few years ago and it was blocked. (P4)"

While not mutually exclusive, disparity in the application of tacit and explicit knowledge within organisations that aim to develop more 'data-guided' socio-technical processes possesses several challenges related to organisational data governance strategies, employee trust in information systems and education. Although the apparent bypassing of explicit knowledge appeared to be the result of several factors that included a 'burden of analysis' imposed on maintainers, both in terms of the time and technical literacy required to interface with centrally managed data repositories, and limited worker understanding of the capabilities available asset information services could offer. 
Maintainer Perspectives on Data-driven Transport Asset Management and the Future Role of the Internet-of-Things

“... we use it [Ellipse] simply as a place to schedule work and to store asset data. It's not a real-time operational asset management tool...(P7)”

In particular, maintainer perceptions of asset inspection information appeared to reinforce their preference. We found the accuracy of the data was often questioned due to concerns that data collectors were not motivated or effectively trained to undertake the reliable in-field data capture. For example, (P4) highlighted a case in Polestar where in their view a series of catch-pits and piping had been incorrectly positioned due to a lack of care by the in-field data collector.

"... you can actually see how he's done that. You can just actually see that he's walked up that track. He may have actually walked down this track, but, also, see the arrows, the flow, it's all wrong... Data is only as good as the quality of the people who input it...(P4)"

Furthermore, issues of data quality appeared to reinforce the need for caution in guiding judgements based on explicit knowledge due to additional factors such as the subjective nature of asset inspections.

\subsection{IoT Analytics \& Automation}

Beyond understanding the application of existing data and decision-support tools our discussions aimed to encourage maintainers to reflect on emerging concepts of real-time asset condition monitoring, predictive drainage analytics and greater levels of automation in planning and decisionmaking. In particular, participants highlighted a series of situated use-cases where IoT and more automated capabilities could benefit their work with further discussions examining likely barriers to future adoption.

5.4.1 Ad-hoc maintenance and dynamic cyclical inspections. Feedback from maintainers suggested greater levels of remote condition monitoring of assets could accelerate a shift to more dynamic forms of maintenance. For example, highways maintainers discussed opportunities to support ad-hoc maintenance as crews executed planned in-field work:

“... if you've got a crew that are local to something... because crews at the moment do work by catchment areas, but if a crew was working close to [a known] problem area, it would make sense and be more efficient ...(P3)"

In rail, sensing instrumentation to capture asset conditions (e.g. silt and water level) was not a new concept to maintainers. Route asset managers and a delivery coordinator described previous trials of remote water-level sensing in 'syphon' drains to support more proactive maintenance capabilities.

"...Yeah that is something that [anonymised] is involved with at the moment, some remote condition monitoring, that's something we're quite keen on developing as a route ...(P5)"

Indeed, at a strategic-level it was suggested that data captured through remote condition monitoring could enable more fine-grained changes in cyclical catch-pit inspection intervals as conditions, and subsequent levels of risk to the railway fluctuated over time. Although, it was emphasised that more dynamic approaches to asset risk management and cyclical inspections would still need to comply with existing drainage maintenance standards and risk policies.

5.4.2 Proactive interventions \& impact mitigation. Maintainers felt the availability of high-resolution asset information could lead to more proactive forms of maintenance, such as identifying problem assets ahead of time, and performing preventative maintenance to mitigate the impact of drainage failure. 
“... our hopes are in a couple of years? time we've got sort of better quality data to try and move away from the reactive maintenance of catch-pits, and look at proactive maintenance in the areas we can show are silting up faster, that sort of thing ...(P5)”

The council's flood risk management team highlighted particular opportunities to utilise predictive analytics support to indicate specific times a road-side gully is likely to flood based on several indicators including silt level and metrological forecasts:

"...I guess the stuff that you want to know is when a gully is likely to fail [flood], under what conditions ... (P2)"

In rail, maintainers gave specific examples where decision-makers could exploit real-time condition data to implement more fine-grained safety measures to mitigate the impact of track floods. Flood events on the rail network typically require infrastructure maintainers to enforce temporary speed restrictions (TSRs) on train operating companies (TOCs) for safety purposes. With speed restrictions correlated to a flood's severity, it is often challenging to implement appropriate restrictions remotely without undertaking a physical inspection of the affected area. It was therefore suggested that drainage monitoring and historical water level information could provide an opportunity to proactively enforce more dynamic TSRs and minimise the impact on rolling.

"... you wouldn't have to reduce the line speed, or you would know how much you would need to reduce it by, rather than having to put a blanket speed across a certain area ...(P9)"

As part of our discussions with highways maintainers a particular future scenario was explored where surface-water flooding had been reported by the public, but nearby sensors embedded in drainage assets had indicated low levels of silt and water. Moreover, P3 highlighted the potential ways in which this data could be used to proactively decide on the type of corrective maintenance intervention to dispatch:

“... if we know it's a tree lined area and the gully's been cleaned out recently we wouldn't send a jetter there, we'd be phoning up [place name omitted] waste [department] to send a road sweeper ...(P3)"

5.4.3 Understanding of drainage asset behaviours. At present, manual inspection regimes of catchpit and road-side gully assets offer a subjective, low-resolution depiction of asset behaviour. It was clear from our engagements that maintainers have a growing dependency on asset information to inform decision-making, but in practice the characteristics of the data (i.e. volume, variability, validity) limited its application in particular aspects of maintenance decision-making.

“...for me it's really about [asset] survey information... because my job initially is all about keeping it [drainage network] going and maintaining it, so as much information as you can give me about the gullies...(P3)"

Maintainers generally expressed the view that remote monitoring and analysis would provide an opportunity to better understand drainage asset performance over time:

“... it would be very good as a research project to understand how quickly catch-pits silt up ...(P7)"

"... so if we can prove that.. say you have the sensors for three years; we could look at that over there years and say this is the sort of average flow rates we had ...(P2)"

Indeed, they further felt such capabilities could support new forms of drainage analytics that could, for example, be used to evidence proposals for new renewal schemes or inform resource planning requests such as track possession times:

"... we could solve some planning applications, if a developer is coming in and building ten houses... we'd want to see their drainage strategy...for how they are going to deal 
Maintainer Perspectives on Data-driven Transport Asset Management and the Future Role of the Internet-of-Things

with drainage so it might be useful for gauging the effectiveness of their drainage strategy ...(P2)"

Beyond opportunities to better understand asset behaviour, maintainers explored potential applications that could utilise both manual inspection and sensor condition data to provide a 'ground-truth' that could be applied to corroborate outputs from predictive drainage models.

"... I guess if a gully crew gets sent out in response to some information then they measure it before they do it... it may say on their devices [predicted] 100\% silt level and then they go there and they measure it and they can compare the measures versus the predicted ...(P2)"

5.4.4 Field operative safety. Manual drainage asset inspection regimes often require maintenance operatives to undertake data collection activities in highly dangerous environments. As a means of reducing worker exposure to risk on the transport network, maintainers felt remote monitoring offered an opportunity to improve worker safety by mitigating the need to undergo frequency visual inspections:

"... as an organisation we are trying to move towards better technology like this, it's not just because it makes the data more reliable but also to try and get the inspectors off the track, or not in a position of safety as often ...(P9)"

At an operational level, maintainers reported the potential benefit of sensing capabilities on segments of infrastructure (i.e. tunnels, motorways with no hard shoulder) where accessibility was often challenging, costly or would lead to a significant impact on travellers on the network:

"...It would be worth it in places like the tunnels if it can, especially underground where we've got major problems with silt build-up ...(P4)"

5.4.5 Prescriptive maintenance \& automated job planning. Automated maintenance scheduling driven by real-time condition monitoring and predictive analytics poses new opportunities to offset the burden of maintenance planning and free-up resource. In general maintainers recognised the potential benefits of a shift towards predictive analytics and automation but underlined several barriers to domain acceptance of the technology.

“...I'm quite in favour of having automated systems.. and I'm quite trusting of that as well, obviously coming from an IT background, it's good to have automated systems like that, if you can get in place a degree of accuracy ...(P1)"

While for highways asset management tasked with gatekeeping operational maintenance budgets, the application of machine-generated maintenance schedules raised significant concern:

“... automatically raise jobs? I don't think that would go down too well with some of the management in the Highways team, because it's obviously jobs cost money, if there's nobody signing them off and approving them, and there's suddenly a big deficit in the annual budget but if it just puts a job in the list to be approved then that's a great system ...(P1)"

In rail, maintainers highlighted concern over the potential laissez-faire nature of a machine-driven scheduler and subsequent challenges of managing maintenance costs:

“... the costs might actually increase because we'll be going into these problem sites earlier ...(P5)"

Maintainers highlighted contractual and regulatory compliance as a barrier towards the application of more prescriptive analytics to inform planning. In particular, guidance and automated schedules would need to be actioned weeks in advance in order for requests for maintenance to be accepted. 
“... because of the lead times involved in scheduling of work, prediction windows would have to be weeks in advance...(P8)"

"...the robustness and reliability of the sensor data was also of concern for many of the maintainers we spoke to, it would have to be robust, if we would have to be easy to fit ...(P7)”

In particular, maintainers who had leveraged sensing capabilities previously raised concern over the impact of human and environmental factors on the performance of sensing capabilities:

"... there are some shortfalls [to sensors], I know it [the sensor] was going crazy one week when there was a spider building a spider's web in front of it ...(P5)"

“...catch-pits when they're cleaned it's quite an attritional process. Shovels of jetters and whatever is in there would have to stay in there and we can't always rely on people to take care of the RCM [remote condition monitoring] ...(P7)"

Concerns over data quality from sensors preceded discussions over the reliability of predictions that leveraged such data to train predictive models and infer future drainage conditions. In particular, maintainers highlighted the importance of understanding the provenance of information before acting upon it:

"...I'd just want to see some evidence that the modelled state of a gully corresponds with the measured state of the gully.. so if it says that the gully needs cleaning because it's at silt level X, I'd want a comprehensive study done and evidence collected that says the system predicted this, we went out and measured it and it was as it said, or it wasn't and by how much ...(P2)"

Overall, while maintainers recognised the benefits of a prescriptive approach, it was suggested its introduction would require a staged implementation within the organisation, that could be assessed and verified over an extended period of time:

“... well I mean I suppose we would never roll it out straightaway it would have to be done on like a trial basis. Um, that's something that we would probably want to prove for ourselves ...(P5)"

5.4.6 Better access to actionable information. Maintainers were shown mock-ups of how descriptive and predictive analytics information might be represented and asked questions about the types of information they would want to view. Maintainers highlighted the need to access previous and planned maintenance work, condition histories and secondary datasets to support decision-making:

"... the history of the gully when it was last cleansed.. if we've done any work on it in the past, and when we did the work, basic information on the gully type because that influences the tools, we'd use...(P3)"

\section{DISCUSSION}

The main and, we believe, substantial contribution of this paper is that it provides a detailed understanding of maintainers' everyday work and, in particular their perspective of data work and attempts to present these empirical findings in relation to some important concepts in the field of IoT and CSCW. In particular, this work builds upon and strengthens some of our early empirical work first reported in $[4,5,30]$. Whilst we would not claim to make any especially new conceptual contributions, we do suggest that this work contributes to an understanding of classic CSCW notions, such as 'awareness' and 'articulation work' in a relatively new domain of drainage maintenance, illustrating the replicability and generalizability of these concepts, and therefore their wider relevance to design work. Our empirical study of drainage maintenance provides 
Maintainer Perspectives on Data-driven Transport Asset Management and the Future Role of the Internet-of-Things

an early characterisation of the work-practices undertaken by several cooperating strategic and operational workers, and the insight into the ways in which approaches to maintenance differ in the application of data and technology across regional boundaries and transport modalities. The drainage maintainers we engaged with represent large-scale organisations that encompass differing perspectives (and sometimes misunderstandings) on how work is done, and on the relative importance of that work. The examination of a broad sample of maintenance roles enabled the articulation of detailed worker perspectives on the role of information and technology in decisionmaking. Such an understanding of drainage maintenance is needed as organisations begin to consider the integration of data-driven decision-support capabilities through emerging IoT and real-time analytic capabilities. Our understanding and characterisation of state-of-the-art drainage maintenance highlights new considerations for the future implementation and acceptance of disruptive technologies, within a challenging domain that has been slow to digitise and modernise. A broader awareness of drainage asset performance through the provision of data represents an attempt to mitigate the compound inefficiencies of drainage maintenance and facilitate new forms of working effectively - that proactively offset the risks associated with drainage failure on the transport network. Evidenced through our respondents' characterisation of maintenance practice, data and technology in decision-making, here we discuss the emerging tensions and opportunities of greater data evolution within transport drainage management in relation to relevant concepts within CSCW.

Indeed, our findings clearly resonate with a number of longstanding issues in CSCW. At its simplest the concern is with a set of issues first highlighted by Grudin in 'Why CSCW applications fail' [14] and extended by Bowers in 'The work to make the network work' [13] - that is, the range and interaction of various technical, human and organisational factors that contribute to the success, or failure, of the deployment of information technology in work settings; and the need to use 'experiences from the field' to shape and reorganise the CSCW research agenda. We have extended this analysis by considering factors relating to the use of data and in particular the future promise of the IoT, contributing to the debate in understanding aspects of 'data work' found in Fischer et al. [11], and the Ludwig et al. [41] notion of an 'internet of practices' through documenting phenomena - drainage maintenance and monitoring - as an aspect of everyday work practice, taking seriously the cooperation between objects (i.e. assets), technology and people that feeds the vision of the IoT as a cooperative enterprise. We reinforce the idea that IoT technologies operate on a number of different contextual levels - the 'internal', the 'socio-material' and the 'task/process' context and point to a range of instances where "considering the IoT on a purely technological basis" misses important points that practitioners have to consider when developing, re-inventing and 'infrastructuring' their practices [41]. This was particularly evident in our speculative discussions around the ideas of remote condition monitoring and concerns around compliance with existing policies on safety and risk mitigation.

This study further contributes to ideas central to CSCW and its interest in 'articulation' work $[17,20]$, 'awareness' $[7,18,19]$ and forms of collaboration [23]. In this project, specific details of second-order articulation work, of allocation, coordination and what Anderson calls 'consociation' [36], and the accountability relations that emerge, with people, technology and data are documented and discussed in terms of their workplace and design relevance and an expanded notion of 'awareness'. These ideas form the basis for future research and technology design and deployment activities. The interest is in how the technologies we describe provide and support various forms of collaboration, articulation and awareness to those responsible for the various kinds of planning and decision making involved in maintenance work. For example, in consideration of more automated maintenance scheduling scenarios we found maintainers demonstrated concern for the potential loss of understanding and control in such a process, and the apparent need for 'awareness' over the 
decisions such systems would undertake. Indeed, this study indicates, as Bowers originally argued, sharing or collaborating around data can create or modify or exaggerate other organisational dilemmas, of responsibility and ownership and control. But the study also suggests some of the ways in which CSCW has effectively moved on in its research agenda, how some of the ideas suggested for improving CSCW are becoming apparent; in the development of more sophisticated awareness mechanisms and the support for network management. We document the varied collaborative methods of data work and decision-making and point to some of the implications this might have for the deployment and use of IoT technologies, the data they capture and the decisions and practices they implicate.

\section{CONCLUSION}

Despite the UK Government's guidance on flood management strategies to mitigate the risk of flood events through the operationalisation of data and informed decision-making, transport infrastructure maintainers have remained relatively slow in transitioning towards a data-driven paradigm. This study attempts to provide an initial characterisation of data and technology application from the case perspectives of both rail and highways drainage maintainers. Moreover, while our primary contribution is rooted in the empirical reporting on maintainers' everyday work, we further attempt to identify and align important CSCW concepts (e.g. data work, awareness, articulation work) as relevant investigative lens going forward to better understand such a highly cooperative work domain and facilitate future design work of data-driven IoT technologies that is sympathetic towards maintainer needs.

Our fieldwork has highlighted several tensions and opportunities that should be of particular interest to both drainage maintainers and system practitioners that are focused on the delivery of technologies that can enable more data-guided cooperative work. Indeed, it is clear that transport drainage maintenance incorporates a range of interleaving manual and cognitive activities undertaken by a diverse range of individuals that still appear to remain dependent on tacit knowledge over the utilisation of emerging silos of business intelligence information, particularly at an operations level. While our work provides early explanation for such behaviours e.g. the current 'burden of analysis' placed on operatives to extract knowledge and mistrust in manually captured information. We believe this work further underlines the importance of first taking a broader situated approach in developing an understanding of 'data work' in this context and how current forms of asset information and existing cooperative work technologies are perceived and consumed, prior to the design and deployment of data-driven IoT systems, recognising the needs of end-users across drainage maintenance roles to heighten the likelihood of future technology acceptance.

\section{ACKNOWLEDGMENTS}

This work has been funded by Innovate UK as part of the "TrackWater: Supporting High-Value, Low-Cost Rail Network Drainage Asset Management" (UKRI/103957) and "Data-driven Precision Surface Water Management for Urban Environments" (UKRI/102353) projects.

\section{REFERENCES}

[1] Environment Agency. 2007. Review of 2007 summer floods. https://assets.publishing.service.gov.uk/government/ uploads/system/uploads/attachment_data/file/292924/geho1107bnmi-e-e.pdf.

[2] Anselm Strauss. 1998. Grounded theory methodology: an overview. Strategies of Qualitative Inquiry (1998). https: //ci.nii.ac.jp/naid/10017375886/en/

[3] Benoit Iung, Eric Levrat, Adolfo Crespo Marquez and Heinz Erbe. 2007. E-MAINTENANCE: PRINCIPLES, REVIEW AND CONCEPTUAL FRAMEWORK. IFAC Proceedings Volumes 40, 19 (2007), 18 - 29. https://doi.org/10.3182/ 20071002-MX-4-3906.00005 1st IFAC Conference on Cost Effective Automation in Networked Product Development and Manufacturing.

Proc. ACM Hum.-Comput. Interact., Vol. 3, No. CSCW, Article 112. Publication date: November 2019. 
[4] Bran Knowles, Mark Rouncefield, Mike Harding, Nigel Davies, Lynne Blair, James Hannon, John Walden and Ding Wang. 2015. Models and Patterns of Trust. (2015), 328-338. https://doi.org/10.1145/2675133.2675154

[5] Bran Knowles, Mike Harding, Lynne Blair, Nigel Davies, James Hannon, Mark Rouncefield and John Walden. 2014. Trustworthy by Design. (2014), 1060-1071. https://doi.org/10.1145/2531602.2531699

[6] Department For Transport (DfT). 2012. Guidance on the management of highway drainage assets. http://www.highwaysefficiency.org.uk/asset/C232B794-31A2-473D-BFAD621B9494119E. D982EF5C-B753-4FF2-9422130073122AFD/.

[7] Gerd Kortuem, Fahim Kawsar, Vasughi Sundramoorthy and Daniel Fitton. 2010. Smart objects as building blocks for the Internet of things. IEEE Internet Computing 14, 1 (Jan 2010), 44-51. https://doi.org/10.1109/MIC.2009.143

[8] UK Government. 2010. Flood and Water Management Act 2010. https://www.legislation.gov.uk/ukpga/2010/29/ contents.

[9] Graham Button and Richard Harper. 1995. The relevance of 'work-practice' for design. Computer Supported Cooperative Work (CSCW) 4, 4 (01 Dec 1995), 263-280. https://doi.org/10.1007/BF01846695

[10] Jana Šelih, Anžej Kne, Aleksander Srdić and Marjan Žura. 2008. Multiple criteria decision support system in highway infrastructure management. Transport 23, 4 (2008), 299-305. https://doi.org/10.3846/1648-4142.2008.23.299-305 arXiv:https://doi.org/10.3846/1648-4142.2008.23.299-305

[11] Joel E. Fischer, Andy Crabtree, James A. Colley, Tom Rodden and Enrico Costanza. 2017. Data Work: How Energy Advisors and Clients Make IoT Data Accountable. Computer Supported Cooperative Work (CSCW) 26, 4 (01 Dec 2017), 597-626. https://doi.org/10.1007/s10606-017-9293-x

[12] Joel E. Fischer, Andy Crabtree, Tom Rodden, James A. Colley, Enrico Costanza, Michael O. Jewell and Sarvapali D. Ramchurn. 2016. "Just Whack It on Until It Gets Hot": Working with IoT Data in the Home. (2016), 5933-5944. https://doi.org/10.1145/2858036.2858518

[13] John Bowers. 1994. The Work to Make a Network Work: Studying CSCW in Action. (1994), 287-298. https: //doi.org/10.1145/192844.193030

[14] Jonathan Grudin. 1988. Why CSCW Applications Fail: Problems in the Design and Evaluationof Organizational Interfaces. (1988), 85-93. https://doi.org/10.1145/62266.62273

[15] K. Anders Ericsson and Herbert A. Simon. 1998. How to Study Thinking in Everyday Life: Contrasting ThinkAloud Protocols With Descriptions and Explanations of Thinking. Mind, Culture, and Activity 5, 3 (1998), 178-186. https://doi.org/10.1207/s15327884mca0503_3

[16] Kaile Zhou, Chao Fu and Shanlin Yang. 2016. Big data driven smart energy management: From big data to big insights. Renewable and Sustainable Energy Reviews 56 (2016), 215 - 225. https://doi.org/10.1016/j.rser.2015.11.050

[17] Kjeld Schmidt. 1994. Cooperative Work and Its Articulation: Requirements For Computer Support. Le Travail Humain 57, 4 (1994), 345-366. http://www.jstor.org/stable/40659884

[18] Kjeld Schmidt. 2002. The Problem with 'Awareness': Introductory Remarks on 'Awareness in CSCW'. Comput. Supported Coop. Work 11, 3 (Nov. 2002), 285-298. https://doi.org/10.1023/A:1021272909573

[19] Kjeld Schmidt and Carla Simone. 1998. Taking the distributed nature of cooperative work seriously. (1998), $295-301$.

[20] Kjeld Schmidt and Liam Bannon. 1992. Taking CSCW seriously. Computer Supported Cooperative Work (CSCW) 1, 1 (01 Mar 1992), 7-40. https://doi.org/10.1007/BF00752449

[21] Lee Carman Ka Man, Cheng Mei Na and Ng Chun Kit. 2015. IoT-Based Asset Management System for HealthcareRelated Industries. International fournal of Engineering Business Management 7 (2015), 19. https://doi.org/10.5772/61821 arXiv:https://doi.org/10.5772/61821

[22] Li Da Xu, Wu He and Shancang Li. 2014. Internet of Things in Industries: A Survey. IEEE Transactions on Industrial Informatics 10, 4 (Nov 2014), 2233-2243. https://doi.org/10.1109/TII.2014.2300753

[23] Liam J. Bannon and Kjeld Schmidt. 1991. Studies in Computer Supported Cooperative Work. (1991), 3-16. http: //dl.acm.org/citation.cfm?id=117730.117731

[24] InTouch Ltd. 2014. Smart Streets Hub Project. https://www.smartstreetshub.com/smart_streets.

[25] Ludwig Trotter, Mike Harding, Mateusz Mikusz and Nigel Davies. 2018. IoT-Enabled Highway Maintenance: Understanding Emerging Cybersecurity Threats. IEEE Pervasive Computing 17, 3 (Jul 2018), 23-34. https://doi.org/10.1109/ MPRV.2018.03367732

[26] Mahmoud R. Halfawy. 2008. Integration of Municipal Infrastructure Asset Management Processes: Challenges and Solutions. Journal of Computing in Civil Engineering 22, 3 (2008), 216-229. https://doi.org/10.1061/(ASCE) 0887-3801(2008)22:3(216)

[27] Mark C. Eti, Stephen O.T Ogaji and Sydney D. Probert. 2006. Reducing the cost of preventive maintenance (PM) through adopting a proactive reliability-focused culture. Applied Energy 83, 11 (2006), 1235 - 1248. https://doi.org/10. 1016/j.apenergy.2006.01.002

[28] Mark Lycett. 2013. Datafication: making sense of (big) data in a complex world. European fournal of Information Systems 22, 4 (2013), 381-386. https://doi.org/10.1057/ejis.2013.10 
[29] Michael D. Meyer, Adjo Amekudzi and John P. O’Har. 2010. Transportation Asset Management Systems and Climate Change: Adaptive Systems Management Approach. Transportation Research Record 2160, 1 (2010), 12-20. https: //doi.org/10.3141/2160-02 arXiv:https://doi.org/10.3141/2160-02

[30] Mike Harding, Bran Knowles, Nigel Davies and Mark Rouncefield. 2015. HCI, Civic Engagement \& Trust. (2015), 2833-2842. https://doi.org/10.1145/2702123.2702255

[31] Muhammad M. Rathore, Awais Ahmad, Anand Paul and Seungmin Rho. 2016. Urban planning and building smart cities based on the Internet of Things using Big Data analytics. Computer Networks 101 (2016), 63 - 80. https: //doi.org/10.1016/j.comnet.2015.12.023 Industrial Technologies and Applications for the Internet of Things.

[32] Paul Sayers, Matt Horritt,Edmund Penning-Rowsell, Andrew McKenzie, David Thompson, F. Klijn and P. Samuels. 2016. The analysis of future flood risk in the UK using the Future Flood Explorer. E3S Web of Conferences 7 (2016) http://nora.nerc.ac.uk/id/eprint/516727/

[33] Chris Penn. 2017. The evolution of the data-driven company. https://www.ibm.com/blogs/business-analytics/ evolution-data-driven-company/. [Online; accessed 1-June-2019].

[34] Pierre W. Jolicoeur and James T. Barrett. 2005. Coming of age: Strategic asset management in the municipal sector. Fournal of Facilities Management 3, 1 (2005), 41-52. https://doi.org/10.1108/14725960510808383 arXiv:https://doi.org/10.1108/14725960510808383

[35] Network Rail. 2018. Safety, Technical and Engineering (STE) An Introduction. https://safety.networkrail.co.uk/ wp-content/uploads/2017/01/Introduction-to-STE.pdf.

[36] Robert J. Anderson and Wes W. Sharrock. 2018. Action at a Distance: Studies in the Practicalities of Executive Management. CRC Press, Routledge, London. 180 pages. https:/www.crcpress.com/ Action-at-a-Distance-The-Practicalities-of-Management/Anderson-Sharrock/p/book/9781138504165

[37] Ron F. Cagle. 2003. Infrastructure asset management: An emerging direction. AACE International Transactions (2003) PM21-PM26. https://search.proquest.com/docview/208184580 Copyright - Copyright American Association of Cost Engineers 2003; Document feature - references; graphs; charts; Last updated - 2014-05-22; SubjectsTermNotLitGenreText - United States; US.

[38] Satya Savitzky. 2018. Scrambled systems: the (im)mobilities of 'storm Desmond'. Mobilities 13, 5 (2018), 662-684. https://doi.org/10.1080/17450101.2018.1466505 arXiv:https://doi.org/10.1080/17450101.2018.1466505

[39] Shuhua M. Liu, Kristene Unsworth, Raya Fidel and Hans J. Scholl. 2007. Fully mobile wirelessly connected technology applications: Organizational communication, social, and information challenges. Proceedings of the American Society for Information Science and Technology 44, 1 (2007), 1-20. https://doi.org/10.1002/meet.1450440237

[40] Steven R. Haynes, Sandeep Purao and Amie L. Skattebo. 2004. Situating Evaluation in Scenarios of Use. (2004), 92-101. https://doi.org/10.1145/1031607.1031624

[41] Thomas Ludwig, Peter Tolmie and Volkmar Pipek. 2019. From the Internet of Things to an Internet of Practices. (2019), 33-47. https://doi.org/10.1007/978-3-319-94659-7_3

[42] Tomás Robles, Ramón Alcarria, Diego Martín, Augusto Morales, Mariano Navarro, Rodrigo Calero, Sofia Iglesias and Manuel López. 2014. An Internet of Things-Based Model for Smart Water Management. (May 2014), 821-826. https://doi.org/10.1109/WAINA.2014.129

[43] Toni Robertson and Ina Wagner. 2015. CSCW and the Internet of Things. (2015), 285-294.

[44] Yvonne Brunetto, Matthew Xerri and Silvia Nelson. 2014. Building a Proactive, Engagement Culture in Asset Management Organizations. Journal of Management in Engineering 30, 4 (2014), 04014014. https://doi.org/10.1061/(ASCE)ME. 1943-5479.0000251

Received April 2019; revised June 2019; accepted August 2019 